\title{
The impact of the patent system on the social welfare: A critical view
}

\author{
Gregorio Giménez (D) \\ University of Zaragoza (Spain) \\ gregim@unizar.es
}

Received April, 2016

Accepted December, 2017

\begin{abstract}
Purpose: This article offers a critical view of the impact of patents on economic activity. The article questions whether a strengthening of the patent system is optimal in economic terms, from a business and social perspective.

Design/methodology/approach: We develop two analytic innovation models. They help us to understand how the strength of the patent system affects 1) the industry profits 2) the social welfare.

Findings: The strengthening of patent systems could cause a decline in the activities of imitation and, therefore, a decrease in competition, a reduction in the production and assimilation of new technologies and could create barriers to entry into technology-intensive sectors, increasing the costs of production. We will show that a lower strength patent system and an increase in the activities of imitation can i) increase the benefits to industry as a whole ii) lead to greater social surplus.

Research limitations/implications: The final set of sustainability-related issues (and drivers) presented aren't exhaustive and are delimited by the particular scenario generated around Aqualogy's business scope; therefore, it cannot be considered as a standard application mode.

Originality/value: Much of the literature on innovation has traditionally seen imitation processes as harmful to the development of new technologies, and detrimental to the welfare of consumers, producers and society at large. That is why policies aimed at strengthening the patent system and discouraging imitation processes are associated with improvements in social welfare, -fostering innovation, trade, foreign investment and technology transfer-. However, our findings should lead us to rethink how optimal innovation policy should be designed. The problems associated with restrictions on the free market involve costs that outweigh the social benefits that patents can provide. Market mechanisms can effectively reward innovators for being the first to bring a product into the market, without the need to grant a monopoly.
\end{abstract}

Keywords: imitation, innovation, patent system, social welfare

Jel Codes: O31, O34, L43 


\section{Introduction}

The recent economic literature finds innovation to have an essential role in economic growth (Helpman, 2004; Aghion \& Howitt, 2009; Acemoglu, 2009; Benhabib, Perla \& Tonetti, 2014). Within this literature, the processes of $\mathrm{R} \& \mathrm{D}$ and technical progress are linked, inextricably, to the development and strength of the patent system (Romer, 1990). Patents allow innovators to recoup some of the huge benefits that their ideas generate and to amortize the high costs of $\mathrm{R} \& \mathrm{D}$ in which they have incurred until the commercial exploitation of their innovations. If their ideas are copied immediately after they appear, this could be a disincentive for innovators, so perfect competition should be restricted for a period of time for inventors to recover their investments and to promote the development of new ideas.

However, in the market, the presence of imitators is common. They coexist with the patent holders and take advantage of new ideas clandestinely. Consequently, imitation is a phenomenon inherent and inextricably linked to the innovation process. Even so, surprisingly, as Eaton and Kortum (1996), Coe, Helpman and Hoffmaister (1997), Mukoyama (2003), Perez-Sebastian (2007) and Johns (2009) point out, most theoretical and empirical literature has refused to recognize the coexistence of innovation and imitation processes or to give the latter the relevance they deserve in the growth literature. Economic models usually consider that the mechanisms that safeguard intellectual property rights (IPR) work efficiently. In these models, monopoly systems derived from the exploitation of patents become mechanisms that encourage the creative process and ensure economic prosperity. When imitation processes are taken into account, they are found to be harmful: they plunder the profits of innovators, discourage the development of innovation and are detrimental to growth (Grossman \& Helpman 1991a, Segerstrom, 1991; Davidson \& Segerstrom, 1998).

However, more and more scholars disagree and argue that imitation processes can have a positive impact on innovation by fostering competition and can contribute decisively to the economic growth of developing countries -and even developed ones. Following this line of argument, this paper attempts to explore the positive aspects of imitation processes on economic activity. Furthermore, contrary to the most widespread view, the paper questions whether a strengthening of the patent system is optimal in economic terms.

The work is structured as follows. Section 2 reviews the conceptual framework of the economic effects of imitation processes. Section 3 analyses what tools can help to strengthen the patent system and the consequences that this policy would have on the processes of innovation and imitation. Sections 4 and 5 set out two models that show that an increase in the activities of imitation, driven by a lower strength patent system, could lead to higher profits for industry and to greater social welfare. Finally, we draw the main conclusions from the paper.

\section{The processes of imitation and its effects on the economy}

The concepts of imitation and innovation have traditionally been antagonistic in the literature. For Sohn (2008, p.75) "imitation, as opposed to innovation, is the act of copying or mimicking the action of others". Similarly, Greenhalgh and Rogers (2010, p. 5) consider that novelty is an inherent characteristic of innovation so that a key issue is "to distinguish innovation, the bringing to the market of a truly novel item, from imitation, the adoption of a new technique or design that is already in the market". This antagonism between the two processes leads to a series of negative and inaccurate beliefs about the processes of imitation. Two of the most common are:

1. To consider that the processes of imitation have little merit from a technical point of view, and are little more than just reverse engineering.

2. To assume, in general terms, that imitation is detrimental to innovation and has serious consequences for the welfare of consumers, producers and society as a whole.

Regarding the first statement, and despite what is commonly thought, Baumol (2004) maintains that imitations have, in many cases, an important innovative component. So, imitators need to adapt products to specific market circumstances, such as the availability of inputs necessary for their manufacturing, consumer preferences and market size. Moreover, these technologies can incorporate many improvements in quality, reliability or ease of use. Studies such as those of Mansfield, Schwartz and Wagner (1981), Levin, Klevorick, Nelson \& Winter (1987) 
and Harabi (1991) empirically confirm that imitation can be more complicated and costly than it may seem at first sight. These three papers show that the ratio of the costs of imitation divided by the costs of R\&D of the innovation is between 0.4 and 0.9 , depending on the complexity of the product and on whether it is patented or not, a factor that complicates the copying process and make it more expensive. Similarly, the time spent on imitation is between 10 months and 2 years, depending on the same characteristics. This means a cost ranging from 0.4 of the time devoted to the innovation to a period that can be longer than that of the innovation process. In many cases, imitation requires tacit knowledge or know-how that the imitating firm does not own and that are relatively inaccessible, at least initially. Along with the high costs, there are other elements that may discourage imitators, such as not having a recognized brand name or entering the market later. Thus, the imitator is an entrepreneur who has to take strategic decisions and develop improvements in his product.

The second common belief, that the processes of imitation are extremely detrimental to welfare, is, in part, a consequence of the information campaigns carried out by governmental institutions and lobbies in developed countries. In a recent report, the United States Government Accountability Office (GAO, 2010) denounces the proportions of the phenomenon in the United States, where seizures of goods infringing IPR (Intellectual Property Rights) by the Department of Homeland Security between 2004 and 2009 amounted to 1.118 million dollars. The report itself sets out a number of potential effects related to the sale of counterfeit and pirates goods (see Table 1).

\begin{tabular}{|l|l|l|}
\hline Stakeholders & \multicolumn{1}{|c|}{ Potencial negative effects } & \multicolumn{1}{|c|}{ Potential positive effects } \\
\hline Consumers & $\begin{array}{l}\text { - Damage to health and safety } \\
\text { - Costs incurred when product fails due to lower quality } \\
\text { of counterfeit good }\end{array}$ & $\begin{array}{l}\text { - Perceived benefits from lower prices of } \\
\text { counterfeit and pirated goods }\end{array}$ \\
\hline Industry & $\begin{array}{l}\text { - Lost sales } \\
\text { - Lost brand value or damage to public image } \\
\text { - Cost of IP protection } \\
\text { - Decreased incentive to invest in R\&D }\end{array}$ & $\begin{array}{l}\text { - Increased sales of legitimate goods based } \\
\text { on consumer "sampling" of pirated goods }\end{array}$ \\
\hline Government & $\begin{array}{l}\text { - Lost tax revenue due to illegal sales of counterfeit and } \\
\text { pirated goods } \\
\text { - Cost of IP enforcement } \\
\text { - Risks of counterfeits entering supply chains with } \\
\text { national security or civilian safety implications }\end{array}$ & \\
\hline Economy as a a \\
whole
\end{tabular}

Table 1. Potential Direct Effects of IPR Infringements in the United States by Stakeholder (GAO, 2010)

As can be seen, the potential damage is greater than the benefits. This damage includes risks to health and safety, waste of public resources and lower economic growth. Innovative companies would be among the most affected, as imitations are a threat to brands. The original products will be seen as less exclusive or may be confused with lower quality copies. Thus, piracy, although it can be profitable for the imitator, creates a negative externality for the innovator. The literature has given more weight to the potential negative impact of counterfeiting than to the positive effects. In growth models based on R\&D, imitation processes are usually seen as harmful to growth, as competition reduces the potential benefits that innovators can obtain. The entry of imitators can lead to them taking away part of the social benefits generated by the innovators, since the imitators incur very low costs compared to those of the discoverer. Grossman and Helpman (1991b) consider that the processes of imitation are characteristic of less developed production systems and end up being detrimental to global economic growth due to their negative impact on innovation activities.

Yet, while the references to the positive effects of imitation are less numerous than the negative ones, some economists have identified a number of important benefits that imitation processes may have on economic welfare, even in such controversial fields as incentives for innovation and growth. 
The GAO report itself notes some of these effects, such as price reductions and advertising associated with sales of counterfeits. Consumers may be aware that the counterfeits are of lower quality. Even so, these consumers would not buy the original product because of its high price, so they seek a product that is more affordable but that, nevertheless, can enable them to enjoy a certain status. This practice can have negative consequences on brand image of the original, whose customers see how their exclusive and expensive products are not really so unique. However, as Grossman and Shaphiro indicate (1988), piracy may also have positive effects because it can mean a form of publicity for the original brand and make the latter look even more exclusive to its products and customers. Peitz and Waelbroeck (2006) agree with this argument. They consider that piracy maybe welfareincreasing, in particular because it leads to market expansion (providing information about the characteristics and value of the product and facilitating the purchasing decision) and because selling physical products that are complements to the information goods mitigates negative effect of piracy on profits. Nevertheless, for Minniti and Vergari (2010) the market expansion effect, that allows firms to reach new costumers, occurs in emerging markets. On the contrary, in mature and widespread markets, firms prefer to be protected from piracy.

Additionally, there are economists who argue that the monopoly power granted by patents to firms will have implications for consumer welfare and may even have negative effects on innovation. For Blundell, Griffith and Van Reenen, (1995), Nickell (1996) and Banerjee and Chatterjee (2010), the introduction of the competition that imitation introduces into innovation processes can have positive effects on the development of new technologies. Cheng and Tao (1999) believe that both innovation and imitation activities contribute to technological advancement, although the role of imitation activities is less recognized. The innovation process will generate new technologies, but these are more easily spread through the processes of imitation. This leads the authors to assert that optimal technological policy should include the provision of subsidies to both innovation and imitation. Mukoyama (2003) shares this point of view. For him, entrepreneurs need to learn from the technologies developed by imitation to create their own technologies. Only the industry leaders within each sector can create significant innovations, while outsiders can enter the sector through the imitation of existing technology and become technology leaders. Thus, the imitation process encourages innovative activity and contributes to economic growth. Subsidizing imitation can be a way of developing technological capacity and enhancing competitiveness. Newly industrialized countries can imitate technologies developed in leader countries and contribute to increasing global welfare, learning to use and adapt them and becoming next round innovators. In this context, Sohn (2008) distinguishes between two possible effects of imitations. One, he calls the pessimistic effect, which causes a reduction of innovation because of the threat of imitators, and the other, the optimistic effect, which results in higher social welfare because of the decline in marginal production costs due to the use of new technologies, either legally or illegally. For him, the optimistic effect is more important, resulting in a net gain of social welfare.

With regard to the effects that imitation processes have on economic growth, Nelson (2007) recalls that, during the nineteenth and early twentieth centuries, in many developing countries, there were no property rights regimes that restricted their companies from copying the innovations available in developed countries. These processes of imitation and adaptation of technologies to specific needs can contribute decisively to the catching up process, as developing countries can become technological powers. The IPR do not constitute an insurmountable barrier if you have the necessary endowments of physical and human capital. In the words of Nelson (2007, p.11), "as the [technological and economic] frontier is approached, the lines between sophisticated imitation and creative design of new products and processes becomes blurry". In fact, authors such as Rosenberg and Steinmueller (1988), Khan and Sokoloff (2006) and Sohn (2008) point out that in countries like Japan, Korea and the United States, imitative activities have contributed decisively to their economic success. Moreover, Hausmann and Rodrik (2003) highlight how, in many developing countries, entrepreneurs or the states themselves have carried out innovative initiatives that have been imitated with great success by other entrepreneurs. This has contributed to development and prosperity. The authors give examples of garments in Bangladesh, cut flowers in Colombia, IT in India and salmon in Chile. It is very unlikely that other local entrepreneurs would have dared to venture into these projects without knowing that the initiative could be profitable. Imitation processes allow punters to bet on winning horses and generate prosperity. In each of the 
cases referred to, the entry of imitators who incorporated some better management is what permitted the local industry to grow, although competition caused some inconveniences for the first entrepreneurs.

Vandenbussche, Aghion and Meghi (2006), Aghion, Boustan, Hoxby and Vandenbussche (2006), Aghion and Howitt (2009), Islam (2010) and López-Pueyo, Barcenilla and Gimenez (In press) relate the processes of innovation and imitation to the degree of development of economies. They conclude that both processes have a key role in growth. On the one hand, the closer the countries are to the technological frontier, the more important the innovation processes will be and, therefore, the more they will invest in higher education. On the contrary, the farther the countries are from the technology frontier, the more important the processes of imitation will be for growth and, therefore, the better it will be to invest in basic educational levels, which are more closely linked to the uptake and use of foreign technologies. Based on the same idea, Perez-Sebastian (2007) develops a model in which imitation is the main source of productivity growth in the early stages of development, while, as economies approach the technology frontier, innovation becomes the engine of growth.

In sum we can conclude that, although the negative effects of imitation (especially on innovation) are often overemphasized, imitation processes can have important positive effects on economic activity: lowering prices and production costs, reducing the monopoly deadweight loss associated to patents, helping to spread new ideas, allowing groups excluded for economic reasons to access goods, promoting competition in business and innovation activities, encouraging efficiency, spurring the development of new innovations adapted to local needs, contributing with ideas and reducing risk in the development of local industries and, finally, helping emerging countries, that are further away from the technology frontier, to converge technologically and economically.

\section{Strength of the patent system, innovation and imitation}

The strength of the patent system substantially affects the development of imitation. We have just seen how the processes of imitation can have significant positive effects on economic activity. Therefore, the following question arises: Does a strengthening of the patent system have economic benefits for society? Although Sections 4 and 5 of the paper will address this issue more fully, first we need to know the mechanisms by which to design a strong patent system and the theoretical arguments used to justify it, the way in which it conditions the processes of innovation and imitation, and its possible effects, both positive and negative, on economic activity. Though intellectual property rights (IPR) include other legal figures -such as copyrights, trademarks, designs and utility models-, when we use the term IPR, we are referring mainly to patents, and we will use the two terms indistinctly.

With regard to the mechanisms that can be used to strengthen the patent system, Andersen (2006, pp. 11-12) notes that the main tools would be: (i) length of IPR protection obtained, (ii) the type of knowledge or creative expression protected (iii) the scope of knowledge protected (iv) the inventive step (v) the licensing law (for example, should we allow the opportunity to block competition or should we opt for compulsory licensing?) and (vi) the costs of and procedures for obtaining and holding a right, and the type and costs of the remedies available for infringement. Another essential element is to provide human and technical resources for the patent offices and the judicial system since, excluding the U.S., where there has been a specialized court to settle patent cases since 1982, in other countries, judges are not specialized in such cases nor, indeed, have the necessary technical and economic knowledge (Cooper, 1993). Finally, it should be said that the instruments used to strengthen the patent system not only require an improvement in the design and implementation of the laws, but also a strengthening of private institutions and mechanisms, available to patent holders, on which the current system relies on.

The fundamental reason put forward to advocate for a strengthening of patent systems is that this can be a critical incentive for innovation. The issue of strengthening IPR protection has transcended local scenarios and has become a major issue in economic relations between countries. We have to keep in mind that the fact that most of the technology stock is in rich countries leads them to have strong economic interests in promoting international respect for IPR. Furthermore, these countries are suffering a growing offshoring of their activities 
to developing economies and, in the exploitation of IPR, through the direct sale of technology and the payment of licensing or royalty fees, they see a source of income from activities in which they still have a significant competitive advantage. That is why the most developed countries consider all matters related to IPR protection as a key in the design of trade policy in a globalized world. Rich countries have been aware of their importance for many years and have sought to establish a system of protection of these property rights by signing international agreements such as the Berne or Paris conventions or the more modern Trade-Related Aspects of the Intellectual Property Rights Section (TRIPS) of the World Trade Organization (WTO). These agreements have provided a major breakthrough in the strengthening of IPR globally. However, some politicians feel that the new international agreements on TRIPS can harm developing countries, since these countries either do not innovate or their innovation activities are very poor. This means that they would become just dependent clients of the rich countries, which would receive a net flow of capital from licensing or royalty fees.

We can find the same disagreements about the strengthening of IPR among economists, especially in regard to how they affect the least developed countries. On the one hand, authors such as Maskus (2000) argue that progress in IPR can have positive effects on trade and technology transfer. This involves the replacement of the processes of imitation by legal transfers, through licensing fees, which, in his opinion, will have a positive outcome because they are lower than the costs of imitation. This view is shared by Khan and Sokoloff (2006), who give the example of the benefits obtained by the United States through the development of its patent system in the early stages of industrialization. This institution favoured the creation of new technologies and the reception of foreign technologies and allowed "ordinary people", who otherwise would have been disadvantaged, to develop and exploit commercially significant discoveries through what the authors call "the role of institutions in fostering democratic invention", p.124. Based on the U.S. experience, we can infer that a development of IPR would have more positive effects in newly industrialized countries than many economists and politicians believe. Park and Ginarte (1997) and Park and Lippoldt (2008) empirically test the positive effects of strengthening the IPR system by constructing a proxy variable that tries to measure the degree of IPR protection in various countries through the quantification of qualitative legal elements. Their findings demonstrate the possible positive effects, such as incentives to trade, reception of foreign investments and technologies, incentives to invest in $\mathrm{R} \& \mathrm{D}$, and incentives to create own technologies and export them. In addition, the authors find that these effects are greater if there are a number of complementary factors associated, such as the quality of infrastructure, the availability of trained human capital, the quality of knowledge institutions (such as academia, public research institutes and industrial research centres), the government policies and regulations, the market structure, the financial system and the availability of networks for research collaboration or interaction.

However, Falvey, Greenaway and Foster (2006) found that, although the positive effects on the development of IPR are clearer in the case of richer and poorer countries, for middle-income newly industrialized countries, stronger IPR may lead to a decline in the activities of imitation and, therefore, in the production and assimilation of new technologies. For North (2005), the creation of patent laws has been an important part of the effort to make the markets of developed countries more efficient. However, the application of these institutional changes to third world economies can lead to political instability and alter the distribution of income, producing negative and undesirable consequences.

Merges and Nelson (1994) point out that a patent policy that is too strict could discourage innovation and impede technical progress. They indicate that there are numerous examples of economies where there has been a rapid technical advance even if the protection of IPR has been weak. Other authors are cautious too about recommending a strengthening of the patent system because of its impact on imitation and due to the beneficial effects of imitation. Klinger and Lederman (2006) point out that, initially, it may be assumed that the threat of imitators can inhibit innovation processes. In theory, the greater the barriers to entry and monopoly power, the lower the threat of imitators and the greater the incentive for innovators to generate discoveries and to expand the range of products for export. However, the econometric evidence presented in their paper shows that, if the barriers to entry are high, potential imitators cannot take advantage of the spillovers generated by entrepreneurs or stimulate new export sectors. Thus, it is important to note that an increase in the barriers to entry does not necessarily result in more discoveries. These barriers tend to occur in economies where private initiative is 
underdeveloped and can lead to the concentration of economic activity in a few sectors. By contrast, imitation activities involve greater competition and lead to the allocation of scarce resources to more profitable activities. Excessive protection may lead to a lack of diversification and the protection of inefficiency.

Greenhalgh and Rogers (2010) identify a number of reasons why the patent system can be detrimental, both to the development of innovation and to growth. Firms sometimes use patents as a strategy to increase the costs of production of new firms, which raises entry barriers in technology-intensive sectors. This problem can be especially acute for smaller companies who find it more difficult to pay the licenses to innovators. Moreover, patent races to see who patents first when firms are researching in the same field cause an apparent waste of resources and lead to inefficiencies. Finally, patents hinder sequential or cumulative innovation. In an analysis of the problems of the U.S. patent system, Bessen and Meurer (2008) detected this aspect, finding firms that do not emit licenses or require exorbitant prices for the use of their patents. These authors also show the high costs of maintaining the system and the patents themselves.

Despite increasing globalization and the international harmonization of laws, each country is free to legislate on patents and there are enormous differences between countries both in legislative aspects and, above all, in the way that the laws are interpreted. We have to keep in mind that small nuances in the interpretation of the rules can lead to big differences in safeguarding property rights.

In conclusion, as Scotchmer (2004) stresses, although we tend to think that strengthening the patent system is always a good idea that leads to the generation of more innovation, this view is too simplistic because, among other reasons, protection systems that are too strong can trigger high deadweight loss due to the monopoly that patents grant, discourage second-round innovations and contribute to the overlap of R\&D costs as firms compete to innovate and be the first to obtain restrictive exploitation rights. Therefore, as we will show in the following sections, strengthening the patent system does not necessarily lead to higher industry profits or more social welfare.

The models that we develop can be applied to wide set of products, services and contexts. We can think in innovators and imitators interacting in the same market or in an international context, in which innovators and imitators coexist in a competitive international scenario.

\section{Strength of the patent system and industry profits}

The strength of the patent system will condition whether imitators can get their products into the market and stay there. Since the presence of imitators entails negative consequences for innovative firms although, as we have shown, it has some significant economic benefits, the purpose of this section is to provide answers to the following questions: i) Are industry profits higher in the absence of imitators? and ii) Does an improvement in the effectiveness of the patent system lead to an increase in these profits?

To do this, we will consider that the industry is made up of two firms: the innovator, who develops a new technology and exploits the monopoly power granted by the patent, and the imitator, who uses the innovation illegally, with varying degrees of success depending on how strong the protection mechanisms of the patent are. Initially, the innovator incurs $R \& D$ costs that we will call $C_{R e r D}$. The mere undertaking of the project of innovation does not guarantee success: risk is inherent in any innovation process. Let xi be a discrete random variable that represents the possibility of the success $\left(x_{1}=1\right)$ or failure $\left(x_{2}=0\right)$ of the innovation project. Let $p(x i)$ be the associated probability function. The corresponding distribution of the probability of success in the innovation project, $S$, will, therefore, has a dichotomous nature, its expected value being:

$$
E[S]=x_{1} p\left(S=x_{1}\right)+x_{2} p\left(S=x_{2}\right)
$$

If the research project is successful, the innovator will patent the resulting idea, which will allow its commercial use in exclusivity during the patent life. When a new technology is commercialized, it often goes through different stages during its life cycle, from its introduction into the market until it finally becomes obsolete. The process of adoption and diffusion of technology has been extensively studied in the economic literature. Stoneman (2002) and Rogers (2003) analyse various methodological proposals that model this process. One of 
the most widely accepted models proposes a Normal distribution of innovation users over time. It is based on the existing differences in tastes, location, needs and consumer habits that lead to the diffusion process of innovation not being uniform among consumers. Following this model, Rogers (2003) suggests that consumers who adopt the technology can be divided into five categories based on standard deviations from the average and depending on the time at which they start to use it: innovators, early adopters, early majority, late majority and laggards, as shown in Figure 1.

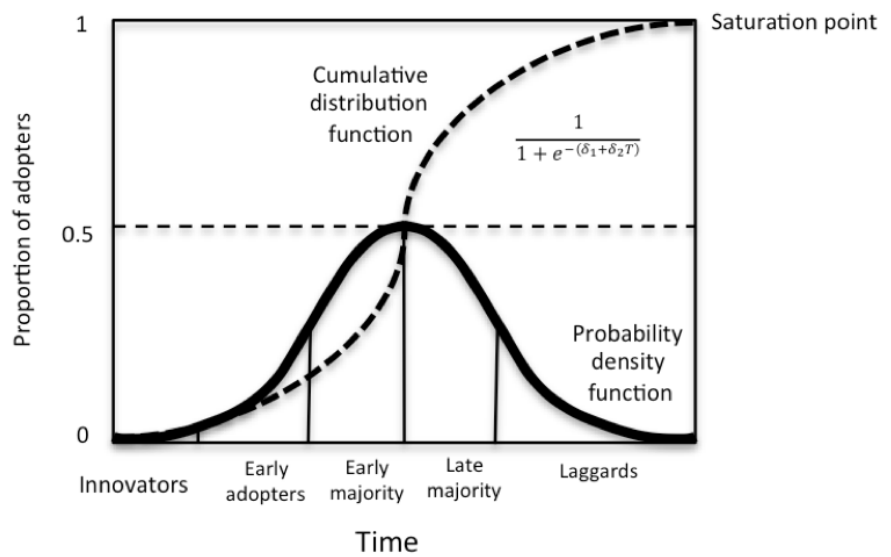

Note: The figure shows the evolution of the fraction of demand adopting the technology along time.

Figure 1. Technology diffusion process based on the Normal distribution

From this figure, we can obtain the cumulative distribution function, which will indicate the percentage of users of the innovation compared with the total potential users over time. It adopts an S-shape, reflecting that the small number of initial users grows with a slope of the curve; which first increases and, then, decreases when it reaches the top of the Normal distribution. The slope is always positive until it reaches the saturation point, where all potential users have acquired the technology and the innovation is replaced by a new one, according to the Schumpeterian creative destruction principle.

Formally, the technological diffusion model we adopt follows this logistic function:

$$
Y_{t}=\frac{1}{1+e^{-\left(\delta_{1}+\delta_{2} t\right)}} \quad t \sim N(0,1)
$$

where $Y_{t}$ represents the proportion of potential users that have adopted the technology in period $t . \delta_{1}$ is a constant of integration that positions the curve on the time scale an $\delta_{2}$ the parameter that indicates the speed of technology adoption. The life cycle of the technology, which will coincide with the period of the patent term, is given by $T$, with $\lim _{t \rightarrow T} Y_{t}=1$

The profits generated over the innovation lifetime are given by the cumulative distribution. For each period, profits are distributed based on the number of users, given the constant of integration and the rate of adoption or slope. If the innovator sells the product exclusively, thanks to the patent, he will seize all the earnings, $G_{\text {inn }}$, over the period $T$ of monopoly.

Thus, the potential profit of an innovative firm, assuming the patent is working efficiently and that there are no imitators in the market, will be $B_{i n n}$, and it will take into account the probability of success of the innovation project, the costs of R\&D and the profits generated by marketing the product throughout its lifetime:

$$
B_{i n n}=\frac{E[S] G_{i n n}}{1+e^{-\left(\delta_{1}+\delta_{2} T\right)}}-C_{R \& D}
$$


However, the presence of only non-imitative firms in the market is an unrealistic assumption. It is difficult to protect IPR effectively and it is common for innovation activities and patents to co-exist with imitation processes that are benefiting illegally from the patented ideas. The fact that the patent is a document available publicly, contributes to its knowledge and diffusion, and means that the innovator assumes a potential risk. No legal system can fully guarantee the protection of IPR. As noted earlier, the strength of the patent system comes from its design and from the efforts of public and private institutions and of the patent holders themselves. The degree of protection will determine how innovative and imitative firms interact in the market and compete to capture the potential profits generated, and conditions two elements:

- The time during which the innovator can act as a monopolist.

- The proportion of profits that the imitator can take away from the innovative firm once the imitations are introduced into the market.

We define $\phi$ as the variable that quantifies how effectively the rights generated by patents are safeguarded.

$$
\phi=f(i) \forall i \in \mathbb{R}^{n} \exists \phi \in[0,1]
$$

It takes values ranging from $\phi=0$, which implies that the patent system is completely ineffective, to $\phi=1$, which means that the system is fully effective and, therefore, there are no imitators in the market.

If the patent system does not work effectively and two firms, one the innovator and the other the imitator, can live in the market, there is a new scenario, in which we can distinguish two periods:

$\mathbf{P 1}$ is a period in which the patent holder can exploit the patent on an exclusive basis. The innovative firm is alone in the market and wields monopoly power -the higher the parameter $\phi$, the longer the period- and obtains a profit:

$$
B_{i n n}^{P 1}=\frac{E[S] G_{i n n}}{1+e^{-\left(\delta_{1}+\delta_{2} T \phi\right)}}-C_{R \& D}
$$

P2 is a period in which the imitating firm competes with the patent holder. While the innovation diffusion function depends on the tastes of consumers and remains unchanged, other changes occur in the potential gains, which are now $G_{i m i}$. These changes are due to the imitating firm selling their copies at a price less than or equal to the monopoly price, among other reasons because the imitation costs that it has to bear are lower than the costs of innovation $\left(i_{R e \dot{ }}^{C} \geq C_{i m i}\right)$. The lower price of the imitations will reduce the number of units sold by the company holding the patent and even, possibly, the price of the original product. Therefore, $G_{i n n} \geq G_{i m i}$. The strength of the patent, as measured by the parameter $\phi$, determines the time that the imitating firm remains in the market and the proportion of earnings that it can take away from the innovator. Given that the costs of development of the innovation have already been included in the previous period, the profits of the two companies will be given by:

$$
\begin{gathered}
B_{i n n}^{P 2}=E[S] G_{i m i} \phi\left[\frac{1}{1+e^{-\left(\delta_{1}+\delta_{2} T\right)}}-\frac{1}{1+e^{-\left(\delta_{1}+\delta_{2} T \phi\right)}}\right] \\
B_{i n n}^{P 2}=G_{i m i}(1-\phi)\left[\frac{1}{1+e^{-\left(\delta_{1}+\delta_{2} T\right)}}-\frac{1}{1+e^{-\left(\delta_{1}+\delta_{2} T \phi\right)}}\right]-C_{i m i}
\end{gathered}
$$

Table 2 summarizes the above, taking into account the benefits that these scenarios, derived from the strength of the patent system, mean for the industry. If the patent system works effectively, the innovator is the only firm that is profitable. If the patent system does not work effectively, the innovator will coexist for a while with the imitating firm. The time during which they coexist and the profits obtained by each of the firms will depend on the strength of the patent system. 


\begin{tabular}{|c|c|c|c|c|}
\hline \multicolumn{2}{|c|}{$\begin{array}{l}\text { Strength of the } \\
\text { patent system } \\
\text { measured } \\
\text { through } \\
\text { parameter } \phi\end{array}$} & \multicolumn{2}{|r|}{ Profits for the innovator } & Profits for the imitator \\
\hline 跑: & $\phi=1$ & & $B_{i n n}=\frac{\mathbb{E}[S] G_{i n n}}{1+e^{-\left(\delta_{1}+\delta_{2} T\right)}}-C_{R \& D}$ & 0 \\
\hline \multirow{2}{*}{ 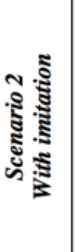 } & \multirow{2}{*}{$0 \leq \phi \leq 1$} & $\begin{array}{l}\overrightarrow{0} \\
\vec{d} \\
\text { d. }\end{array}$ & $B_{i n n}^{P_{1}}=\frac{\mathbb{E}[S] G_{i n n}}{1+e^{-\left(\delta_{1}+\delta_{2} T \phi\right)}}-C_{R \& D}$ & 0 \\
\hline & & त्. & $B_{i n n}^{P 2}=\mathbb{E}[S] G_{i m i} \phi\left[\frac{1}{1+e^{-\left(\delta_{1}+\delta_{2} T\right)}}-\frac{1}{1+e^{-\left(\delta_{1}+\delta_{2} T \phi\right)}}\right]$ & $B_{i m i}^{P 2}=G_{i m i}(1-\phi)\left[\frac{1}{1+e^{-\left(\delta_{1}+\delta_{2} T\right)}}-\frac{1}{1+e^{-\left(\delta_{1}+\delta_{2} T \phi\right)}}\right]-C_{i m i}$ \\
\hline
\end{tabular}

Table 2. Strength of the patent system and benefits for industry

Table 2 will help us to answer the two questions posed initially. The first is whether the benefits generated in the industry with an efficient patent system, in which only the innovator exploits the innovation, are superior to those of a scenario in which the patent system is inefficient and allows the coexistence, albeit limited, of the innovator and the imitator. This can be answered considering:

$$
B_{i n n}>B_{i n n}^{P 1}+B_{i n n}^{P 2}+B_{i m i}^{P 2} \leftrightarrow B_{i n n}-\left(B_{i n n}^{P 1}+B_{i n n}^{P 2}+B_{i m i}^{P 2}\right)>0
$$

Calculating the inequality (8) yields:

$$
\begin{aligned}
& \frac{\mathbb{E}[S] G_{i n n}}{1+e^{-\left(\delta_{1}+\delta_{2} T\right)}}-C_{l+D} \\
& -\left(\frac{\mathbb{E}[S] G_{i n n}}{1+e^{-\left(\delta_{1}+\delta_{2} T \phi\right)}}-C_{I+D}+\mathbb{E}[S] G_{i m i} \phi\left[\frac{1}{1+e^{-\left(\delta_{1}+\delta_{2} T\right)}}-\frac{1}{\left.1+e^{-\left(\delta_{1}+\delta_{2} T \phi\right.}\right]}\right]+G_{i m i}(1-\phi)\left[\frac{1}{1+e^{-\left(\delta_{1}+\delta_{2} T\right)}}-\frac{1}{\left.\left.1+e^{-\left(\delta_{1}+\delta_{2} T \phi\right)}\right]-C_{i m i}\right)}\right.\right. \\
& =\frac{e^{2 \delta_{1}+\delta_{2}(T+T \phi)}+C_{i m i}\left(1+e^{\delta_{1}+\delta_{2} T}\right)\left(1+e^{\delta_{1}+\delta_{2} T \phi}\right)+\mathbb{E}[S] G_{i n n}+\left(e^{\delta_{1}+\delta_{2} T \phi}\right) G_{i m i}(1+(-1+\mathbb{E}[S]) \phi)+\left(e^{\delta_{1}+\delta_{2} T}\right)\left(1+\mathbb{E}[S] G_{i n n}+G_{i m i}(-1+\phi-\mathbb{E}[S] \phi)\right)}{\left(1+e^{\delta_{1}+\delta_{2} T}\right)\left(1+e^{\delta_{1}+\delta_{2} T \phi}\right)}\left\{\begin{array}{l}
> \\
=
\end{array}\right\} 0
\end{aligned}
$$

That is, in general, it cannot be said that the industry profits generated when the patent system ensures that the innovator exploits the patented product under a monopoly are higher than those earned in the presence of imitators.

To address the second issue, that is, whether an improvement in the effectiveness of the patent system will lead to an increase in the profits of the industry, we must ask how changes in $\phi$ affect the total industry profits. Formally:

$$
\frac{d\left(B_{i n n}^{P_{1}}+B_{i n n}^{P_{2}}+B_{i m i}^{P_{2}}\right)}{d \phi}=\frac{e^{\delta_{1}}\left(e^{\delta_{2} T}-e^{\delta_{2} T \phi}\right)(-1+E[S]) G_{i n n}}{\left(1+e^{\delta_{1}+\delta_{2} T}\right)\left(1+e^{\delta_{1}+\delta_{2} T \phi}\right)}\left\{\begin{array}{l}
> \\
< \\
=
\end{array}\right\} 0
$$

Thus, in general, it cannot be said that a stronger patent system will lead to an increase in industry profits.

To sum up, in both the cases described, the result depends on the strength of the patent system, the probability of success of the innovation project, the specific characteristics of the copy -which, together with the strength of the patent regime, will determine the differences in gains between the two firms- and on how the innovation is diffused in the market. In the first case, moreover, it depends on the value of the costs of imitation. These results lead us to reconsider the adequacy of industrial and innovation policies that impulsively advocate a stronger patent system, a comprehensive analysis of the relevant variables being necessary. 


\section{Strength of the patent system and social welfare}

Patents ensure that innovative firms can sell their products on an exclusive basis, which means that the sale price is above the marginal cost of production. However, for the patent holder, the relevant production cost is not the marginal, but the average cost. Only a sale price equal to or greater than the average cost will allow him to recover his high investment in R\&D. The recovery of these costs is one of the main arguments to justify the monopoly exploitation of new ideas. However, the patent system leads to a market that works inefficiently, since society has to bear the presence of a deadweight loss and, consequently, a social welfare loss. This is due to the fact that some consumers are willing to pay a price above the marginal cost for the product but, as this price is below the monopoly price, they will be outside the market. This is one of the main reasons why the patent system is questioned by some economists and many potential consumers. So, is social welfare bigger if the patent system works efficiently and the innovator is the only one who exploits the innovation? Can the presence of an imitator increase social welfare?

Figure 2 shows patent monopoly and welfare. The innovative firm sells $x\left(p_{m}\right)$ units of product at the monopoly price $p_{m}$. We assume that the marginal cost of producing each unit is zero. As Romer (1990) suggests, the assumption of low or close to zero marginal costs is common in the case of innovations that require high R\&D costs. Therefore, area $S$, which is below the demand curve $D$, represents the consumer surplus that would accrue in a competitive market. $S=S(\pi+\omega+\varepsilon)$, with $\pi+\omega+\varepsilon=1$. Deadweight loss will be $\varepsilon S$. The net social welfare is calculated by subtracting the initial costs of development of the innovation, $C_{R e r D}$, from the innovator gains and the consumer surplus, that is: $S(\pi+\omega)-C_{R e r D}$. To find the total social welfare in the life of the innovation, which we believe coincides with the period of exploitation of the patent, $T$, we have to multiply the social welfare of each period by $T$, resulting in: $\operatorname{TS}(\pi+\omega)-C_{\text {Rér } D}$.

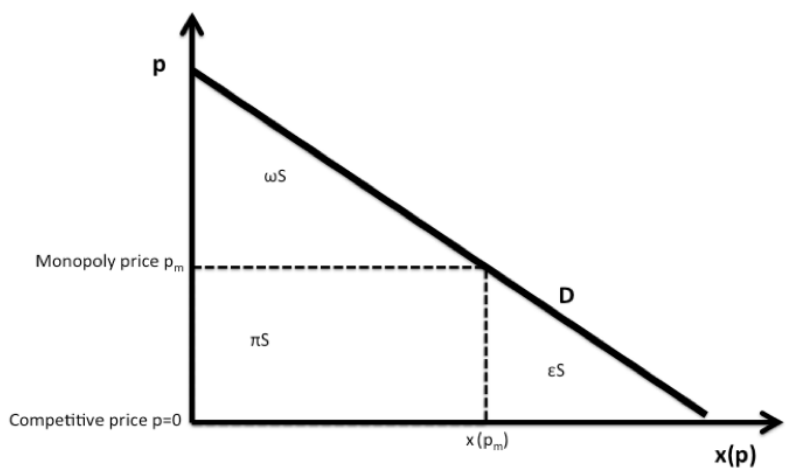

Figure 2. Patent monopoly and welfare

As noted above, to consider that the patent system works effectively and that there are no imitators is an unrealistic assumption. So, let us suppose the presence of an imitating firm which is in the market together with the innovative firm. The activity of the imitating firm will be marked by the effectiveness of the patent system. Again, we use the variable $\phi$ to quantify how effectively the rights generated by patents are safeguarded. It takes values ranging from $\phi=0$, which implies that the patent system is absolutely ineffective, to $\phi=1$, which means that the system is fully effective and, therefore, there are no imitators in the market.

$$
\phi=f(i) \forall i \in \mathbb{R}^{n} \exists \phi \in[0,1]
$$

Any ineffectiveness in the functioning of the patent system and the presence of imitators are usually seen as economic inefficiencies that reduce social welfare. But, can the presence of an imitator in the market increase social welfare? To answer this question, we will consider two scenarios: a baseline scenario in which the patent system works effectively and a second in which ineffectiveness in the operation of the patent system allows the existence of an imitator. Both are depicted in Figure 3. In the second scenario, the fact that a competitor offers a similar product at a lower price will mean a decline in sales. This is represented by a shift in the demand curve, which passes from $\mathrm{D}_{1}$ to $\mathrm{D}_{2}$. The imitator will have a demand curve $\mathrm{D}_{3}$, which will allow him to sell $\chi_{\text {imi }}$ units at a price $P_{i m i}<P_{m}$. This differentiated demand curve arises because consumers perceive differences associated with 
product quality, brand image and customer service, among others. We will use Figure 3 to calculate changes in the social surplus associated with the two scenarios.

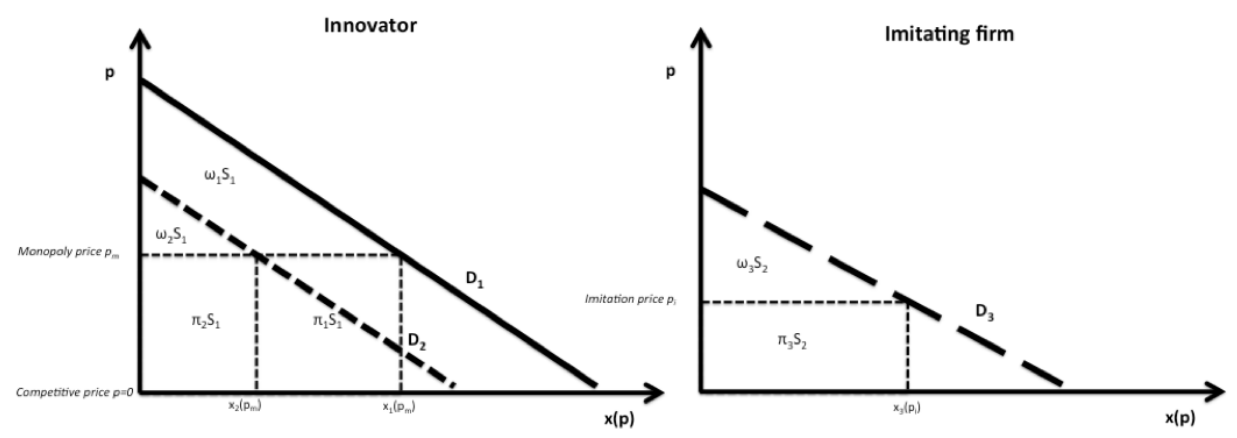

Figure 3. Innovator, imitator and social welfare

\section{Scenario 1: in which the patent system works effectively, $\phi=1$.}

The social surplus is given by the sum of the innovator gains and the consumer surplus generated in each period minus the development costs of innovation:

$$
S S^{1}=T\left(\pi_{1}+\pi_{2}+\omega_{1}+\omega_{2}\right) S 1-C_{R \dot{R} D}
$$

Scenario 2: in which the patent system does not work effectively, $\Phi \epsilon[0,1)$.

We can distinguish two periods:

\section{P1 is the period in which the patent holder can exploit it on an exclusive basis.}

To calculate the social surplus associated with the innovator when it is the only firm in the market, we must take into account that the period of exclusivity will be $T \phi$ :

$$
S S^{2, P 1}=T \phi\left(\pi_{1}+\pi_{2}+\omega_{1}+\omega_{2}\right) S 1-C_{R \dot{R} D}
$$

\section{P2 is the period in which the imitating firm competes with the patent holder.}

For the rest of the lifecycle of innovation, $T(1-\phi)$, the innovator will coexist with the imitator and total social surplus, bearing in mind that we have already accounted for $C_{I+D}$, and that the costs of imitation are given by $C_{i m i}$, will be:

$$
S S^{2, P 2}=T(1-\phi)\left[\left(\pi_{2}+\omega_{2}\right) S_{1}+\left(\pi_{3}+\omega_{3}\right) S_{2}\right]-C_{i m i}
$$

Table 3 summarizes the above, and shows the social surplus arising from the scenarios that represent the strength of the patent system. If the patent system works effectively, consumers may choose to purchase the innovation at the monopoly price set by the patent holder. If the patent system does not work effectively, consumers will be able to choose between the patented product and its copy. The length of the time during which the copy is supplied depends on the strength of the patent system. The imitating firm incurs a cost of imitation that is lower than the initial innovation sunk costs that the innovating firm supports. This guarantees that the imitator can supply the product at a price that may be lower than the average production cost, which is the limit price for the innovator. This allows more consumers to choose to consume the good, resulting in an increase in consumer surplus and a social gain. 


\begin{tabular}{|c|c|c|c|c|}
\hline \multicolumn{2}{|c|}{$\begin{array}{l}\text { Strength of the patent } \\
\text { system measured } \\
\text { through parameter } \phi\end{array}$} & \multicolumn{2}{|r|}{ Social surplus generated by the innovator } & \multirow{2}{*}{$\begin{array}{c}\text { Social surplus generated by the imitator } \\
0\end{array}$} \\
\hline 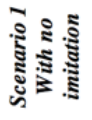 & $\phi=1$ & & $\mathbf{S S}^{1}=\mathrm{T}\left(\pi_{1}+\pi_{2}+\omega_{1}+\omega_{2}\right) \mathbf{S}_{1}-C_{R \& D}$ & \\
\hline \multirow{2}{*}{ 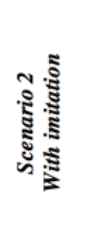 } & \multirow{2}{*}{$0 \leq \phi \leq 1$} & $\begin{array}{l}\overrightarrow{0} \\
.0 \\
0 \\
0.0\end{array}$ & $\mathrm{SS}^{2, \mathrm{P}_{1}}=\mathrm{T} \phi\left(\pi_{1}+\pi_{2}+\omega_{1}+\omega_{2}\right) \mathrm{S}_{1}-C_{R \& D}$ & 0 \\
\hline & & 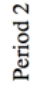 & $\mathrm{SS}^{2, \mathrm{P} 2}=\mathrm{T}(1-\phi)\left(\pi_{2}+\omega_{2}\right) \mathrm{S}_{1}$ & $\mathrm{SS}^{2, \mathrm{P} 2}=\mathrm{T}(1-\phi)\left(\pi_{3}+\omega_{3}\right) \mathrm{S}_{2}-C_{\text {imi }}$ \\
\hline
\end{tabular}

Table 3. Strength of the patent system and social welfare

To test when the net social surplus is higher (when the patent system works effectively or in the presence of imitators), we will calculate the variation that occurs in the net social surplus when the imitator enters the market. We will have to calculate the net social surplus, that is, after discounting, first, the deadweight loss associated with a higher selling price than the marginal cost and, second, the initial costs of innovation and imitation, $C_{R e r} D$ and $C_{i m i}$. Social welfare will be higher when the patent system efficient if, and only if:

$$
S S^{1}-S S^{2, P 1}-S S^{2, P 2}>0
$$

That is, if:

$$
\begin{aligned}
& T\left(\pi_{1}+\pi_{2}+\omega_{1}+\omega_{2}\right) S_{1}-C_{R e \dot{D} D}-T \phi\left(\pi_{1}+\pi_{2}+\omega_{1}+\omega_{2}\right) S_{1}+C_{R e \dot{D} D}-T(1-\phi)\left[\left(\pi_{2}+\omega_{2}\right) S 1+\left(\pi_{3}+\omega_{3}\right) S_{2}\right] \\
& \quad+C_{i m i}>0 \Leftrightarrow T(1-\phi)\left[\left(\pi_{1}+\omega_{1}\right) S_{1}-\left(\pi_{3}+\omega_{3}\right) S_{2}\right]<C_{i m i} \Leftrightarrow T(1-\phi)\left[\left(\pi_{3}+\omega_{3}\right) S_{2}-\left(\pi_{1}+\omega_{1}\right) S_{1}\right]>C_{i m i}
\end{aligned}
$$

From this expression, we can extract the following corollaries:

Corollary 1: The social surplus generated by a patent system that works effectively and with no imitators in the market will be greater than the social surplus generated by a patent system that works ineffectively and with imitators in the market if, and only if, the difference between the consumer net surplus of the innovator and the imitator -after discounting the deadweight losses produced during the time that both firms are in the market and the gains generated by selling at a price higher than the marginal cost- is less than the imitation costs that the imitator has to bear to get the product into the market.

Corollary 2: The social surplus generated by a patent system that works ineffectively and with imitators in the market will be greater than the social surplus generated by a patent system that works effectively and with no imitators in the market if, and only if, the difference between the consumer net surplus of the innovator and the imitator -after discounting the deadweight losses produced during the time that both firms are in the market and the gains generated by selling at a price higher than the marginal cost- is greater than the imitation costs that the imitator has to bear to get the product into the market.

Therefore, it cannot be said that the social surplus is greater if the patent system is strengthened, since it will depend on the magnitude of the costs of imitation and the demand characteristics of the innovator and the imitator, that is, on product differentiation and on their elasticities of demand. We will have to analyse all these elements with caution before we advocate for policies based on a strengthening of patent systems for the sake of greater social welfare.

\section{Concluding Remarks}

In these pages, we have shown how the literature on innovation has often seen the imitation process as harmful to the development of innovation, bad for growth and detrimental to the welfare of consumers, producers and society at large. That is why policies aimed at strengthening the patent system and discouraging imitation 
processes are associated with improvements in social welfare, -fostering innovation, trade, foreign investment and technology transfer.

Although the negative effects are always emphasized, imitation processes can have significant positive effects on economic activity. Among these, we could highlight that they encourage innovative activity and constitute a first step in developing their own innovations, contributing decisively to the process of convergence among the countries further away and closer to the technological frontier. They also stimulate competition in innovation processes, allow excluded consumers access to products, may represent advertising for the original brand, help to disseminate new ideas and stimulate the development of new innovations adapted to local needs.

Hence, the strengthening of patent systems could cause a decline in the activities of imitation and, therefore, a decrease in competition, a reduction in the production and assimilation of new technologies and could create barriers to entry into technology-intensive sectors, increasing the costs of production.

Consequently, as we have shown:

- In general, it cannot be said that the profits generated in the industry when the patent system ensures that the innovator exploits the patented innovation under monopoly are higher than those produced in the presence of imitators. Nor can it be said that a stronger patent system will lead to an increase in industry profits. The result will depend on many factors, such as the probability of success of the innovation project, the characteristics of the copy, the imitation costs and the manner in which the innovation is diffused in the market.

- Neither can we say that, if the patent system ensures that there are no imitators in the market, social surplus will be higher, since it will depend on factors such as the costs of imitation, the differentiation between the copy and the original product and their elasticity of demand.

All this should lead us to rethink how optimal innovation policy should be designed. This should help to reconcile incentives to innovate and social welfare maximization. In line with the arguments used by Boldrin and Levine (2008), discoverers have the right to own and sell their ideas, but not to control them once they are sold, which in legal terms is known as the exhaustion or first sale doctrine. Market mechanisms can effectively reward innovators for being the first to bring a product into the market, without the need to $g$ rant a monopoly. Thus, the problems associated with restrictions on the free market, because of the monopoly conferred by patents, especially by limiting the use of new ideas by other innovators, involve costs that outweigh the social benefits that patents can provide.

There are well-known examples on how an innovation system that shares knowledge without restraints can encourage innovation; and hence economic activity and social welfare. In the 1980's and 1990's, when the first treatments to fight AIDS epidemic appeared, they had a very high cost. This made impossible, for patients in poor countries, to access treatment. The powerful Indian pharmaceutical industry began to copy the patented drugs in 2000. This allowed a huge reduction in their price and facilitated access to treatment. Many poor countries benefited. In addition, Indian practices allowed the combination of several drugs in a single pill, which both reduced the production costs and made treatment more effective. All this could not be done with the patent laws in vigour.

As a result of this and other similar cases, in recent years, different social movements have emerged demanding free access to knowledge. A good example are free software communities, which share an open source. In a society where access to software is becoming a key aspect linked to the success in education and work, this software can be freely modified, redistributed and used. Another one is the use of the current IPR system, but under new forms -such as creative commons and patent lefts- that allow sharing innovations and facilitate their use.

This 'collective knowledge' is making knowledge more equitable and accessible. The evaluation of the economic impact of these new forms of sharing knowledge will be a fundamental line of research in the coming years. 
Thus, the calculation of the economic value that represents open licenses, free software and some aspects of the collaborative economy related to the diffusion of knowledge means to test empirically the importance of free knowledge diffusion for businesses and society. This type of research will suppose an empirical extension of the models developed in these pages and will back the ideas showed.

\section{Declaration of Conflicting Interests}

The authors declared no potential conflicts of interest with respect to the research, authorship, and/or publication of this article.

\section{Funding}

The author(s) received no financial support for the research, authorship, and/or publication of this article.

\section{References}

Acemoglu, D. (2009). Introduction to modern economic growth. Princeton University Press, Princeton, NJ.

Aghion, P., Boustan, L., Hoxby, C., \& Vandenbussche, J. (2006). Exploiting states' mistakes to identify the causal impact of higher education on growth. (ISNIE Conference Paper).

Aghion, P., \& Howitt, P. (2009). The economics of growth. MIT Press, Cambridge, Mass.

Andersen B. (Ed.) (2006). Intellectual property rights: Innovation, governance and the institutional environment. Edward Elgar, In. Cheltenham, U.K. https://doi.org/10.4337/9781847201522

Baumol, W. J. (2004). Difusión y adaptación de la tecnología: El crecimiento a través de la innovación imitativa. ICE, March-April(814), 5-16.

Banerjee, D., \& Chatterjee, I. (2010). The impact of piracy on innovation in the presence of technological and market uncertainty. Information Economics and Policy, 22 (4), 391-397.

https://doi.org/10.1016/j.infoecopol.2010.09.005

Benhabib, J., Perla J., \& Tonetti, C. (2014). Catch-up and fall-back through innovation and imitation. Journal of Economic Growth, 19(1), 1-35. https://doi.org/10.1007/s10887-013-9095-z

Bessen, J., \& Meurer, M. J. (2008). Patent failure: How judges, bureaucrats, and lanyers put innovators at risk. Princeton University Press, Princeton, NJ.

Blundell, R., Griffith, R., \& Van Reenen, J. (1995). Dynamic count data model of technological innovations. Economic Journal, 105, 333-344. https://doi.org/10.2307/2235494

Boldrin, M., \& Levine, D. K. (2008). Against intellectual monopoly. Cambridge University Press, New York.

Cheng, L. K., \& Tao, Z. (1999). The impact of public policies on innovation and imitation: The role of R\&D technology in growth models. International Economic Review, 40(1), 187-207. https://doi.org/10.1111/14682354.00011

Coe, D. T., Helpman, E., \& Hoffmaister, A. W. (1997). North-South R\&D spillovers. Economic Journal, 197, 134149. https://doi.org/10.1111/1468-0297.00146

Cooper, A. C. (1993). Challenges in predicting new firm performance. Journal of Business Venturing, 8(3), 241253. https://doi.org/10.1016/0883-9026(93)90030-9

Davidson, C., \& Segerstrom, P. (1998). R\&D subsidies and economic growth. RAND Journal of Economics, 29(3), 548-577. https://doi.org/10.2307/2556104

Eaton, J., \& Kortum, S. (1996). Trade in ideas: Patenting and productivity in the OECD. Journal of International Economics, 40, 251-278. https://doi.org/10.1016/0022-1996(95)01407-1 
Falvey, R., Greenaway, D. \& Foster, N. (2006). Intellectual property rights and economic growth. Review of Development Economics, 10(4), 700-719. https://doi.org/10.1111/j.1467-9361.2006.00343.x

GAO United States Government Accountability Office (2010). Observations on Effots to Quantify the Economic Effects of Counterfeit and Pirated Goods. Report to Congressional Committees. GAO-10-423 Intellectual Property Series.

Greenhalgh, C., \& Rogers, M. (2010). Innovation, intellectual property and economic growth. Princeton University Press, Princeton, NJ. https://doi.org/10.2307/j.ctt1zgwjjb

Grossman, G. M, \& Helpman, E., (1991a). Innovation and growth in the global economy. MIT Press, Cambridge, Mass.

Grossman, G. M. \& Helpman, E. (1991b). Endogenous product cycles. Economic Journal, 101(408), 1214-1229. https://doi.org/10.2307/2234437

Grossman, G. M., \& Shapiro, C. (1988). Foreign counterfeiting of status goods. Quarterly Journal of Economics, 103(1-February), 79-100. https://doi.org/10.2307/1882643

Harabi, N. (1991). Innovation versus imitation: Empirical evidence from swiss firms. Munich Personal RePEc Archive MPRA, Paper n²6214. (Retrieved on 12 May 2011 from http://mpra.ub.uni-muenchen.de/26214/)

Hausmann, R., \& Rodrik, D. (2003). Economic development as self-discovery. Journal of Development Economics, 72(2), 603-633. https://doi.org/10.1016/S0304-3878(03)00124-X

Helpman, E. (2004). The mystery of economic growth. Belknap Press of Harvard University Press, Cambridge, Mass.

Islam, M. R. (2010). Human capital composition, proximity to technology frontier and productivity growth. Monash Economics Working Papers, n²3-10. (Retrieved on 15 January 2011 from:

http://monash.academia.edu/RabiulIslam/Papers/375166/Human Capital Composition Proximity to Technology F rontier and Productivity Growth)

Johns, A. (2009). Piracy: The intellectual property wars from Gutenberg to gates. The University of Chicago Press, Chicago. https://doi.org/10.7208/chicago/9780226401201.001.0001

Khan, B. Z., \& Sokoloff, K. L. (2006). Institutions and technological innovation during early economic growth: Evidence from great inventors in the united states, 1790-1930. In: T. S. Eicher, C. García-Peñalosa (Eds.), Institutions, development, and economic growth (pp. 307)

Klinger, B., \& Lederman, D. (2006). Diversification, innovation, and imitation inside the global technological frontier. World Bank Policy Research, Working Paper 3872(April). https://doi.org/10.1596/1813-9450-3983

Levin, R., Klevorick, K., Nelson, R., \& Winter, S. (1987). Appropriating the returns from industrial research and development. Brookings Papers on Economic Activity, Special Issue on Microeconomics, 783-821. https://doi.org/10.2307/2534454

López-Pueyo, C., Barcenilla, S., \& Giménez, G. (In press). The two faces of human capital and their effect on technological progress. Panoeconomicus, OnLine-First, Issue 00. https://doi.org/10.2298/PAN151002014L

Mansfield, E., Schwartz, M., \& Wagner, S. (1981). Imitation costs and patents: An empirical study. The Economical Journal, 91(364-December), 907-918. https://doi.org/10.2307/2232499

Maskus, K.E. (2000). Intellectual property rights in the global economy. Institute for International Economics, Washington, D.C.

Merges, R. P., \& Nelson, R. R. (1994). On limiting or encouraging rivalry in technical progress: The effect of patent scope decisions. Journal of Economic Behavior \& Organization, 25(1), 1-24. https://doi.org/10.1016/01672681(94)90083-3 
Minniti, A., \& Vergari, C. (2010). Turning piracy into profits: A theoretical investigation. Information Economics and Policy, 22(4), 379-390. https://doi.org/10.1016/j.infoecopol.2010.06.001

Mukoyama, T. (2003). Innovation, imitation, and growth with cumulative technology. Journal of Monetary Economics, 50(2), 361-380. https://doi.org/10.1016/S0304-3932(03)00005-9

Nelson, R. R. (2007). The changing institutional requirements for technological and economic catch up. International Journal of Technological Learning, Innovation and Development, 1(1), 4-12. https://doi.org/10.1504/IJTLID.2007.015016

Nickell, S. J. (1996). Competition and corporate performance. Journal of Political Economy, 104, 724-746. https://doi.org/10.1086/262040

North, D. C. (2005). Understanding the process of economic change. Princeton University Press, Princeton, N.J. https://doi.org/10.1515/9781400829484

Park, W. G., \& Ginarte, J. C. (1997). Intellectual property rights and economic growth. Contemporary Economic Policy, 15(3), 51-61. https://doi.org/10.1111/j.1465-7287.1997.tb00477.x

Park, W. G., \& Lippoldt, D. C. (2008). Technology transfer and the economic implications of the strengthening of intellectual property rights in developing countries. OECD Trade Policy Working Papers, no. 62. https://doi.org/10.1787/244764462745

Peitz, M., \& Waelbroeck, P. (2006). Piracy of digital products: A critical review of the theoretical literature. Information Economics and Policy, 18(4), 449-476. https://doi.org/10.1016/j.infoecopol.2006.06.005

Perez-Sebastian, F. (2007). Public support to innovation and imitation in a non-scale growth model. Journal of Economic Dynamics \& Control, 31, 3791-3821. https://doi.org/10.1016/j.jedc.2006.12.011

Rogers, E. M. (2003). Diffusion of innovations (5th Ed.). The Free Press, New York

Romer, P. M. (1990). Endogenous technological change. Journal of Political Economy, 98(5), S71-102. https://doi.org/10.1086/261725

Rosenberg, N., \& Steinmueller, W. E. (1988). Why are Americans such poor imitators? American Economic Review, $78(2$ (May)), 229-234.

Scotchmer, S. (2004). Innovation and incentives. MIT Press, Cambridge, Mass.

Segerstrom, P. S. (1991). Innovation, imitation, and economic growth. Journal of Political Economy, 99(4(August)), 807-829. https://doi.org/10.1086/261779

Sohn, S. J. (2008). The two contrary effects of imitation. Economic Modelling, 25(1), 75-82. https://doi.org/10.1016/j.econmod.2007.04.009

Stoneman, P. (2002). The economics of technological diffusion. Blackwell Publishers, Oxford; Malden, MA.

Vandenbussche, J., Aghion, P., \& Meghi, C. (2006). Growth, distance to frontier and composition of human capital. Journal of Economic Growth, 11(2), 97-127. https://doi.org/10.1007/s10887-006-9002-y

\section{(c) (1) (9)}

Article's contents are provided on an Attribution-Non Commercial 4.0 Creative commons International License. Readers are allowed to copy, distribute and communicate article's contents, provided the author's and Intangible Capital's names are included. It must not be used for commercial purposes. To see the complete license contents, please visit https://creativecommons.org/licenses/by-nc/4.0/. 